\title{
The Midbrain Periaqueductal Gray Control of Respiration
}

\author{
Hari H. Subramanian, ${ }^{1}$ Ron J. Balnave, ${ }^{2}$ and Gert Holstege ${ }^{1}$ \\ ${ }^{1}$ Center for Uroneurology, University Medical Center Groningen, University of Groningen, 9700 RB Groningen, The Netherlands, and ${ }^{2}$ School of Medical \\ Sciences, University of Sydney, Lidcombe, New South Wales 1825, Australia
}

The midbrain periaqueductal gray (PAG) organizes basic survival behavior, which includes respiration. How the PAG controls respiration is not known. We studied the PAG control of respiration by injecting D,L-homocysteic acid in the PAG in unanesthetized precollicularly decerebrated cats. Injections in different parts of the PAG caused different respiratory effects. Stimulation in the dorsomedial PAG induced slow and deep breathing and dyspnea. Stimulation in the dorsolateral PAG resulted in active breathing and tachypnea consistent with the respiratory changes during fright and flight. Stimulation in the medial part of lateral PAG caused inspiratory apneusis. Stimulation in lateral parts of the lateral and ventrolateral PAG produced respiratory changes associated with vocalization (mews, alternating mews and hisses, or hisses). D,L-Homocysteic acid injections in the caudal ventrolateral PAG induced irregular breathing. These results demonstrate that the PAG exerts a strong influence on respiration, suggesting that it serves as the behavioral modulator of breathing.

Key words: midbrain; emotional breathing control; pattern generation; periaqueductal gray; brainstem; respiration

\section{Introduction}

Cell groups in the medullary and pontine lateral tegmental field are thought to control respiration (von Euler, 1983; Feldman, 1986; Long and Duffin, 1986). The inspiration-related cell groups differ from those related to expiration. Some of the inspirationrelated cell groups contain premotor interneurons that project to the phrenic and external intercostal muscle motoneurons in the cervical and thoracic spinal cord, respectively (Holstege and Kuypers, 1982; Lipski et al., 1983; Duffin and Lipski, 1987; Holstege, 1991b). Expiration-related nuclei contain interneurons projecting to the internal intercostal and abdominal muscle motoneurons in the thoracic and upper-lumbar spinal cord (Holstege and Kuypers, 1982; Miller et al., 1989; Holstege, 1991b). Together, these premotor respiration-related centers regulate cyclic breathing (or eupnea) on the basis of afferent information from the pulmonary mechanoreceptors (lung volume, stretch, and airway receptors) and from peripheral chemoreceptors in the carotid arteries measuring $\mathrm{pCO}_{2}$ and $\mathrm{pO}_{2}$ levels in the blood (von Euler, 1983; Feldman, 1986; Long and Duffin, 1986). Most of this information enters the brainstem via the vagal nerve. One might consider the caudal brainstem respiration-related cell groups as reflex centers that maintain, increase, or decrease the respiratory frequency (RF), depending on pulmonary and chemoreceptor afferent information. However, this reflex system is not sufficient for proper survival behavior. In case sudden events in the surrounding of the individual represent danger, fight or flight reac-

Received Sept. 2, 2008; revised Sept. 25, 2008; accepted 0ct. 1, 2008.

This work was supported by grants from the Faculty of Health Sciences, The University of Sydney (H.H.S.). H.H.S. was a recipient of an Australian National Health and Medical Research Council Neuroscience postgraduate scholarship and Balmain Hospital research assistantship.

Correspondence should be addressed to Gert Holstege, Center for Uroneurology, University Medical Center Groningen, University of Groningen, Postbus 30.001, 9700 RB Groningen, The Netherlands. E-mail: g.holstege@med.umcg.nl.

DOI:10.1523/JNEUROSCI.4168-08.2008

Copyright $\odot 2008$ Society for Neuroscience $\quad$ 0270-6474/08/2812274-10\$15.00/0 tions might be necessary, which includes immediate rapid shallow breathing. Other strong anxiety reactions necessitate gasping or vocalization. The caudal brainstem premotor respirationrelated cell groups do not receive from vagal afferents information concerning the external environment. To adjust respiration to survive threatening events, a mediator is necessary that receives visual, auditory, and somatosensory information and has access to respiration-related cell groups in the caudal brainstem. We hypothesize that this mediator is the midbrain periaqueductal gray (PAG). The PAG, by way of its projections to the respiration-related cell groups in the caudal brainstem, can change the eupneic breathing pattern into respiratory function appropriate for the situation. However, studies about the PAG control of respiration in the cat do not exist except in the context of vocalization. In these studies (Magoun et al., 1937; Bandler and Carrive, 1988; Zhang et al., 1994; Nonaka et al., 1999; Nakazawa et al., 2000), the sound production was measured but not the respiratory function. In the rat, a few studies exist (Huang et al., 2000; Hayward et al., 2003, 2004; Zhang et al., 2005, 2007; Subramanian et al., 2007, 2008), but they were limited to the dorsal PAG showing only an increase in respiratory frequency. The present study is the first that investigated the PAG effects on respiration by stimulation of different parts of the PAG. We studied not only the changes in respiratory phase durations but also the intratracheal pressure and the diaphragmatic, intercostal, and abdominal muscle EMG patterns after stereotaxic chemical stimulation of different parts of the PAG.

\section{Materials and Methods}

Surgery. Approval for these studies was obtained from the Institutional Animal Care Ethics Committee of the University of Sydney. Eight cats (weighing between 2.2 and $4.5 \mathrm{~kg}$ ) were used. They were anesthetized in a box filled with a mixture of isoflurane and oxygen delivered by a ventilation pump. After induction, the anesthesia was maintained through a face mask, and femoral arterial and venous catheters were inserted. Using the intravenous catheter, sodium thiopental $(10-20 \mathrm{mg} / \mathrm{kg}$ ) was injected 

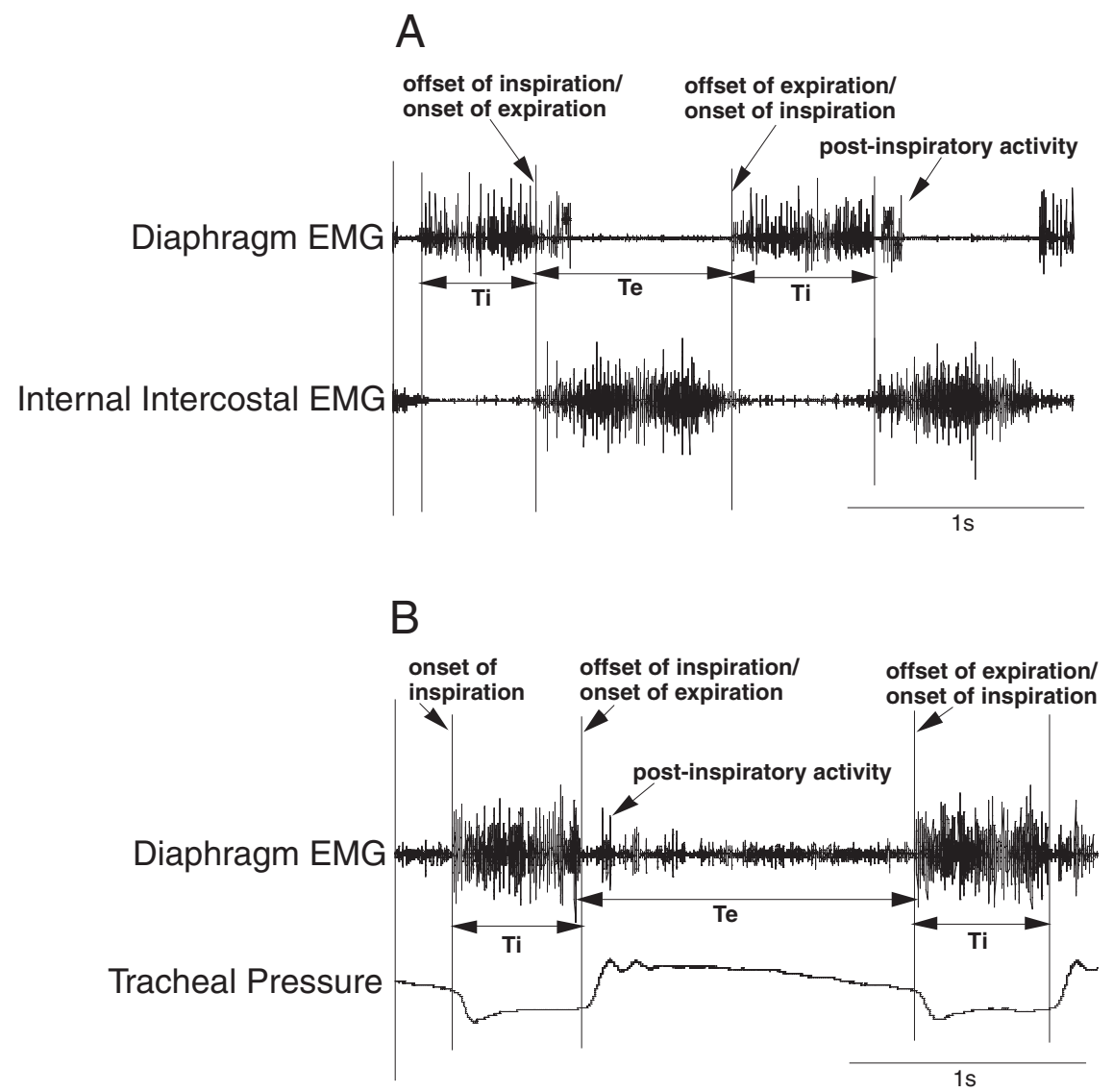

Figure 1. Illustration of Tiand Te measured from the raw diaphragm EMG signal. The diaphragm EMG activity is compared with internal intercostal EMG $(\boldsymbol{A})$ or tracheal pressure $(\boldsymbol{B})$ while locating the start and fall of its activity.

to enable the insertion of an endotracheal catheter, which was then used for the administration of isoflurane. The cat's head was secured in a stereotaxic frame with the body suspended from the frame by straps. To allow access to the midbrain, two burr holes were drilled in the skull on either side of the sagittal sinus. The dura was then incised and the medial part of the cortex was suctioned. After ligation and removal of a portion of the sagittal sinus, precollicular decerebration was performed using suction diathermia, a surgical technique that uses pulsations of electrical energy to generate heat and cauterize blood vessels to prevent excessive bleeding while suctioning brain tissue. Bleeding during decerebration was reduced by lowering the mean arterial pressure from 100-130 to 65-70 $\mathrm{mmHg}$ by raising the level of anesthesia. All brain tissue rostral to the superior colliculus including the entire diencephalon was removed. After completion of decerebration, anesthesia was discontinued. The cat started breathing spontaneously and the mean arterial pressure returned to $100-130 \mathrm{mmHg}$ within $30-60 \mathrm{~min}$. A thermostatic infrared lamp was used to maintain the animal body temperature at $37.5-38.5^{\circ} \mathrm{C}$. The end-tidal $\mathrm{CO}_{2}$ (measured by means of a Morgan 901 gas analyzer) was intermittently monitored. Fluid supplements were administered via the femoral intravenous catheter.

Chemical stimulation in the PAG. Excitatory amino acid [D,Lhomocysteic acid (DLH); 200 mm; Sigma-Aldrich] microinjections were used for stimulation in the PAG. For these injections, a pressure system (Picospritzer II; Parker Instrumentation) was connected to a singlebarrel glass micropipette (tip diameter, $10-30 \mu \mathrm{m}$ ). This micropipette was inserted into different parts of the PAG guided by stereotaxic coordinates, because previous studies (Bandler and Carrive, 1988; Bandler and Depaulis, 1991; Behbehani, 1995) have shown that different portions of the PAG have different effects in the context of survival behavior. The injected volume of DLH was determined by using a precalibrated scale. To eliminate the effect of a previous injection, the interval between microinjections was at least $25 \mathrm{~min}$. Rhodamine beads were added to the
DLH solution for later histological identification of the injection sites. At the end of each experiment, the animal was deeply anesthetized and perfused transcardially with $0.9 \%$ saline followed by $4 \%$ paraformaldehyde in phosphate buffer, $\mathrm{pH}$ 7.2. After perfusion, the brain was removed and stored in $4 \%$ formaldehyde for $2 \mathrm{~h}$. It was then transferred to a $30 \%$ sucrose/ formaldehyde mixture for at least $48 \mathrm{~h}$ to prevent ice crystal formation. The midbrain was cut on a freezing microtome into $50 \mu \mathrm{m}$ coronal sections. The injection sites marked with rhodamine were identified using fluorescent microscopy and were represented on standard drawings according to the stereotaxic atlas of Berman (1968).

EMG recording. Unilateral EMG activity was recorded using bipolar Teflon-coated, multistranded stainless-steel electrodes, bared for 2 $\mathrm{mm}$ at their tips. The electrodes were surgically implanted in the crural diaphragm and in a selection of cricothyroid, internal intercostal, internal and external abdominal oblique, and genioglossus muscles. A maximum of four muscle EMGs could be recorded simultaneously and analyzed during each PAG stimulation. A 19gauge needle was inserted into the trachea and connected to a differential pressure transducer to record the changes in tracheal pressure. Mean arterial pressure was recorded through the catheter placed in the femoral artery and obtained from the low-pass-filtered pressure pulses. The mouth of the cat was kept open, and vocalization was recorded with a microphone placed $10 \mathrm{~cm}$ from the mouth.

Data analysis. The bandpass-filtered (0.1-5 $\mathrm{kHz}$ ) respiratory and laryngeal muscle EMG activity as well as other signals such as tracheal pressure, mean arterial pressure, and the sound of vocalization, were recorded on the "Pulse Code Modulator" (PCM) (A. R. Vetter) and played back for analysis using the PCM/MacLab/Apple system and Chart software (ADInstruments). The recording started at least $60 \mathrm{~s}$ before the administration of DLH. After the injection, the recording continued for at least $5 \mathrm{~min}$. Statview software running on an Apple computer was used for the computation of inspiratory time (Ti), expiratory time (Te), and $\mathrm{RF}$ as well as for statistical comparisons, which were performed using ANOVA. Significant differences between the mean values were detected using Scheffé's least difference test. A probability of $<0.05$ was considered significant. Chart records have been transformed into MacDraw Pro software for data representation.

Measurement of respiratory durations and frequency. The raw diaphragm EMG signal was used for measurement of inspiratory (Ti) and expiratory $(\mathrm{Te})$ durations and RF. The duration from the onset of the diaphragm signal to its offset was defined as Ti. The duration between the offset of the diaphragm and its subsequent onset was defined as Te. The exact points of onset and offset of inspiration was determined via comparison of the diaphragm EMG with internal intercostal EMG (Fig. 1 $A$ ) or tracheal pressure signal (Fig. $1 B$ ).

\section{Results}

Spontaneously breathing vagiintact precollicularly decerebrated cats $(n=8)$ had the following respiratory and cardiovascular parameters (control values expressed as mean $\pm \mathrm{SE}$ ): $\mathrm{Ti}, 0.60 \pm$ $0.05 \mathrm{~s}$; Te, $0.90 \pm 0.05 \mathrm{~s} ; \mathrm{RF}, 40 \pm 4$ breaths $/ \mathrm{min}$; blood pressure (BP), $105 \pm 5 \mathrm{mmHg}$; heart rate, $199 \pm 5$ beats/min; arterial blood pH, $7.39 \pm 0.05 ; \mathrm{p}_{\mathrm{a}} \mathrm{CO}_{2}, 25.2 \pm 5.0$ Torr; $\mathrm{p}_{\mathrm{a}} \mathrm{O}_{2}, 110.5 \pm$ 10.0 Torr. All animals had postinspiratory activity in the crural diaphragm but only during eupnea. The postinspiratory activity 

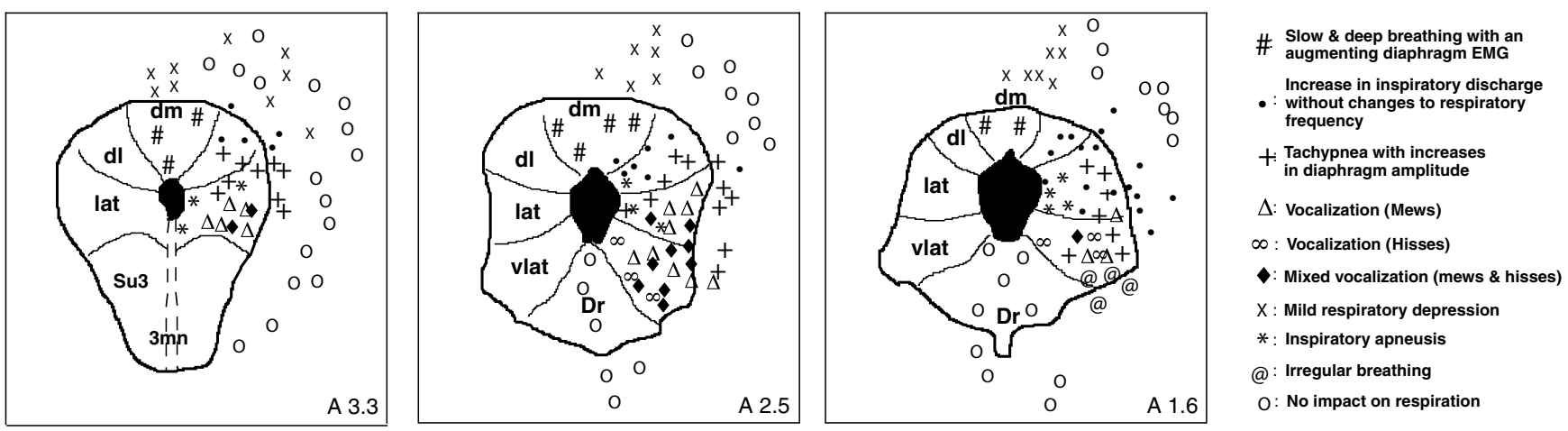

Figure 2. The PAG stimulation sites and the responses evoked. Midbrain PAG schematics are based on those of Berman (1968). Approximate location of brain site relative to bregma in millimeters is shown. dm, Dorsomedial column; dl, dorsolateral column; lat, lateral column; vlat, ventrolateral column; Su3, supraoculomotor PAG; 3mn, oculomotor nuclei; Dr, dorsal raphe.

lasted for $10.5 \pm 5.0 \%$ of eupneic Te. The postinspiratory pause was in the order of $0.01-0.04$ s. Figure 2 illustrates the location of the injection sites inside and outside the PAG and the elicited respiratory changes. An average of 32 with a maximum of 40 microinjections was made in each animal. At each stereotaxic position, the injections were repeated three times (with an interval of $25 \mathrm{~min}$ between the injections) for testing the reproducibility of the effect evoked from that region. The injections in the same animal in the same PAG region always had the same effect. The subdivision of the PAG in dorsomedial, dorsolateral, lateral, and ventrolateral PAG was made on the basis of subdivisions proposed by Holstege (1991a) and Bandler and Depaulis (1991).

\section{Stimulation in the dorsomedial PAG}

DLH injections $(30 \mathrm{nl})$ in the area dorsal to, but outside the dorsomedial PAG resulted in a mild decrease in respiratory frequency. EAA microinjections (DLH; 200 $\mathrm{mm} ; 30-60 \mathrm{nl}$ ) into the dorsomedial PAG evoked a breathing response $(n=8)$ that was characterized by a decrease in RF. The diaphragm EMG exhibited a strong augmenting discharge pattern (Fig. $3 A$ ) without postinspiratory activity. A $30 \mathrm{nl} \mathrm{DLH}$ microinjection reduced the respiratory frequency from 40 to $26 \pm 4$ breaths/min $(p<0.05)$, leading to an extension of Te from $0.90 \pm 0.05$ to $4.0 \pm 2.0 \mathrm{~s}(p<0.05)$. Ti remained relatively unchanged $(0.55 \pm$ $0.03 \mathrm{~s} ; p<0.05)$. This breathing pattern persisted up to $3 \mathrm{~min}$ after which the normal breathing pattern resumed. The respiratory response was accompanied by an increase in BP from $105 \pm$ 5 to $145 \pm 5 \mathrm{mmHg}(n=8 ; p<0.05)$ and an increase in heart rate from $199 \pm 5$ to $220 \pm 5$ beats $/ \min (p<0.05)$. A $60 \mathrm{nl} \mathrm{DLH}$ injection (Fig. $3 B$ ) resulted in a much stronger depression than a $30 \mathrm{nl}$ injection with respiration lapsing into apnea (apneic episodes of up to $20 \mathrm{~s}$ ).

\section{Stimulation in the dorsolateral PAG}

Outside the dorsolateral PAG (dlPAG), DLH microinjections elicited almost no effect on respiration, but within the dIPAG two distinct types of breathing responses were induced. The first type of breathing response was predominantly found after stimulating broad areas of the dIPAG. It was characterized by conversion of passive respiration to active respiration by recruitment of expiratory musculature. During this response, an increase of the inspiration time and a decrease of expiration time was observed. The respiration frequency did not change. The second breathing type was tachypnea found after stimulation within areas bordering the lateral PAG. It was characterized by a rapid increase in respiratory frequency combined with strong increase in the diaphragm EMG amplitude.

During the first type of breathing response (i.e., active breathing response) $(n=12)$ (Fig. $4 A)$, a $30 \mathrm{nl}$ DLH microinjection elicited an increase of Ti from $0.60 \pm 0.05$ to $1.0 \pm 0.50 \mathrm{~s}(p<$ 

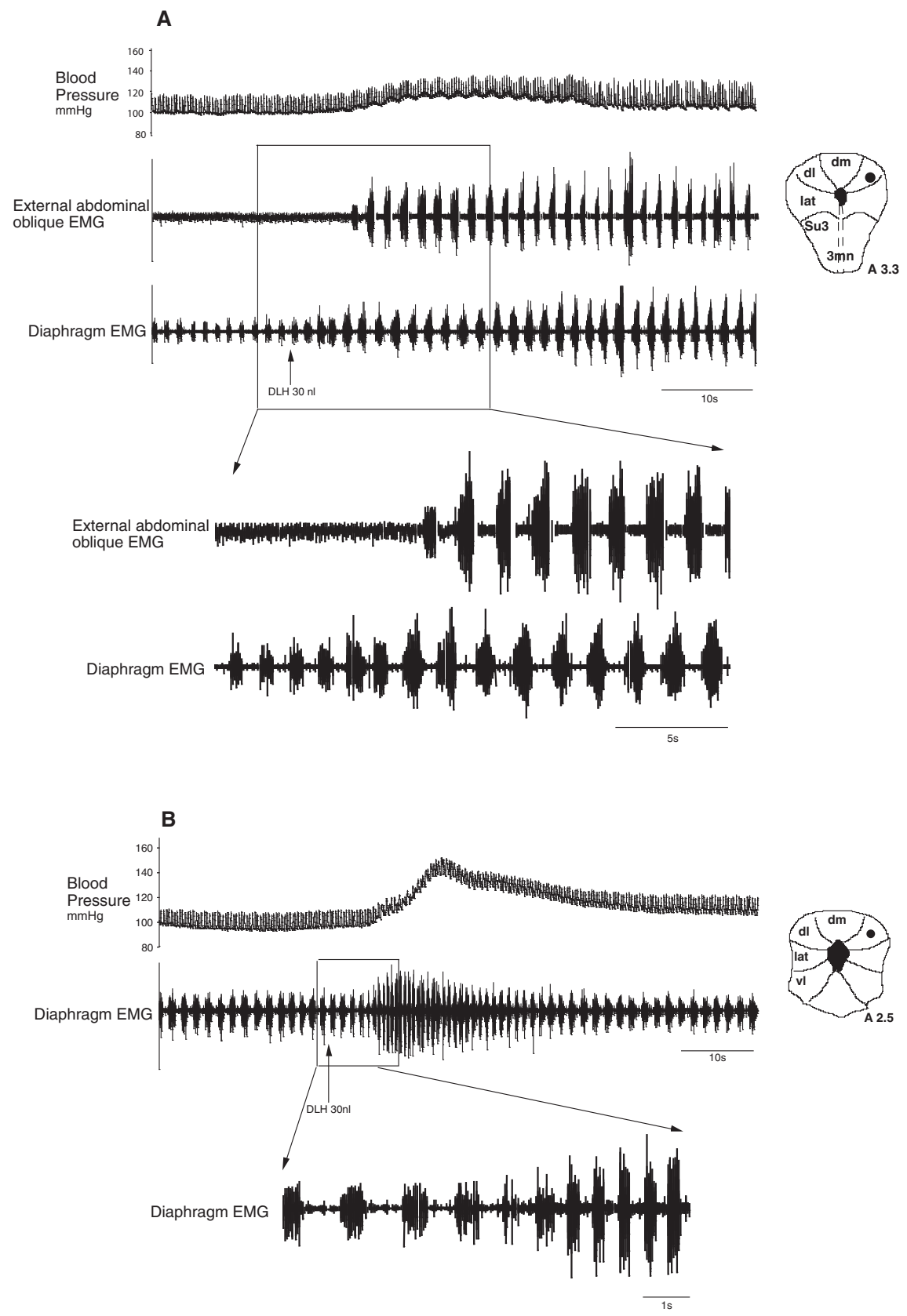

Figure 4. $A$, Injection of DLH in the dorsolateral PAG elicited an increase in the inspiratory duration, decrease in the expiratory duration, but no change in the respiratory frequency. $\boldsymbol{B}$, In another case, DLH injection in the dorsolateral PAG resulted in tachypnea characterized by a decrease in both inspiratory and expiratory durations and consequent increase in the respiratory frequency. In both effects, an increase in the diaphragm amplitude can be seen.

$0.05)$ and a decrease of Te from $0.90 \pm 0.05$ to $0.55 \pm 0.03 \mathrm{~s}(p<$ $0.05)$, leaving the respiratory frequency relatively unchanged (39 \pm 2 breaths/min; $p>0.05$ ). In addition, a strong increase of the diaphragm EMG amplitude, blood pressure $[105 \pm 4$ to $120 \pm 2 \mathrm{mmHg}(p<0.05)]$, and heart rate $[199 \pm 5$ to $220 \pm 5$ beats/min $(p<0.05)$ ] was observed. The diaphragm did not exhibit any postinspiratory activity. There was also recruitment of the external abdominal oblique muscle.

During the second type of breathing response (i.e., tachypnea) $(n=5)$ (Fig. $4 B)$, a $30 \mathrm{nl}$ DLH injection elicited a rapid rise in the respiratory frequency from $40 \pm 2$ to $84 \pm 5$ breaths $/ \min (n=6$; $p<0.05)$, caused by a decrease of both $\operatorname{Ti}(0.25 \pm 0.02 \mathrm{~s} ; p<0.05)$ and $\mathrm{Te}(0.50 \pm 0.03 \mathrm{~s} ; p<0.05)$. There was a strong increase of the diaphragm EMG amplitude, but no postinspiratory activity. This tachypnea was accompanied by a blood pressure increase from $105 \pm 5$ to $150 \pm 5 \mathrm{mmHg}$ $(n=6 ; p<0.05)$ and a heart rate increase from $199 \pm 5$ to $250 \pm 10$ beats $/ \mathrm{min}(n=$ $6 ; p<0.05)$.

\section{Stimulation in the lateral PAG}

EAA microinjections in the lateral PAG (A3.3-A2.5) evoked three types of breathing responses: (1) tachypnea $(n=9)$ similar to the one observed stimulating the dorsolateral PAG (see above), (2) inspiratory apneusis $(n=9 ; p<0.05)$, and (3) respiratory changes in the context of vocalization $(n=13 ; p<0.05)$.

The second effect, inspiratory apneusis (Fig. 5A), was obtained from especially the medial part of the lateral PAG and was characterized by prolongation of inspiration up to $8 \mathrm{~s}$ after a $30 \mathrm{nl}$ DLH injection. No postinspiratory activity was seen in the diaphragm EMG and no cardiovascular changes were observed.

The third type of respiratory change produced by $30 \mathrm{nl}$ DLH injections in the lateral PAG was a transient vocal response lasting 2-5 s. Larger injections ( $90 \mathrm{nl}$ ) elicited much longer vocal episodes (20-120 s). The main type of vocalization elicited from the lateral PAG $(n=9)$ was mews, consisting of recruitment of genioglossus, cricothyroid (Fig. $5 B$ ), external abdominal oblique (Fig. 6A), and internal intercostal and internal abdominal oblique muscles (Fig. 6B). The contraction of these muscles caused an increase in the tracheal pressure of up to $40 \mathrm{~cm} \mathrm{H}_{2} \mathrm{O}$ leading to vocalization (Fig. 6C). The vocalization effect evoked from the lateral PAG represented in Figures 5 and 6 are from different DLH (90 nl) injections.

During mew episodes, the respiratory frequency strongly decreased from $40 \pm 3$ to $26 \pm 5$ breaths/min $(n=10 ; p<0.05)$. The $\mathrm{Ti}$ showed a small reduction from $0.60 \pm 0.05$ to $0.50 \pm 0.01 \mathrm{~s}(p<0.05)$, and the diaphragm did not exhibit postinspiratory activity. The Te was prolonged, from $0.9 \pm 0.05 \mathrm{~s}$ to an average of $2.0 \pm 0.50 \mathrm{~s}$ ( $p<0.05 \mathrm{vs})$, with a maximum expiratory vocal time of $5 \mathrm{~s}$.

\section{Stimulation in the ventrolateral PAG}

Stimulation in the ventrolateral PAG produced a mixed vocal response $(n=8)$ consisting of alternating long mews and short hisses accompanied by a so-called "double diaphragm" breathing pattern (Fig. 7A). The sequence was generally mew, inspiration, hiss, inspiration, mew, inspiration, hiss, etc. A hiss was characterized by small changes in tracheal pressure (up to $6 \mathrm{~cm} \mathrm{H}_{2} \mathrm{O}$ ) and small recruitments of the external oblique abdominal muscle (Fig. $7 B$ ). The Ti preceding the hiss was generally longer than in eupnea, whereas the Te during the hiss was shorter. During the 
entire mixed vocal episode, Ti increased from $0.60 \pm 0.05$ to $0.70 \pm 0.05 \mathrm{~s}(p<$ $0.05)$, Te decreased from $0.90 \pm 0.05$ to $0.50 \pm 0.05 \mathrm{~s}(p<0.05)$, and the respiratory frequency decreased considerably from $40 \pm 3$ to $12 \pm 3$ breaths $/ \min (p<$ $0.05)$. In most cases $(n=8 ; p<0.05)$, this mixed vocalization episode was preceded by tachypnea (Fig. 7C), which started $\sim 10$ $\mathrm{s}$ after a $90 \mathrm{nl}$ DLH injection and continued until the start of vocalization $(\sim 30 \mathrm{~s}$ after DLH injection). This tachypneic episode was similar to that observed after DLH injection in the dorsolateral and lateral PAG. During this tachypnea, a positive shift in the baseline of the cricothyroid muscle EMG was seen (Fig. 7C).

In three cases $(p<0.05)$, the DLH injection generated a "multiple diaphragm" breathing pattern (Fig. 8A) consisting of two to four short inspirations before a mew, but without any hisses.

In six cases, a train of only hisses was evoked $(p<0.05)$ (Fig. $8 B$ ) from the medial part of the ventrolateral PAG. During such a train, the respiratory frequency increased from $40 \pm 3$ to $63 \pm 3$ breaths $/ \mathrm{min}$ $(p<0.05)$ because of a reduction of $\mathrm{Te}$ from $0.90 \pm 0.05$ to $0.40 \pm 0.02 \mathrm{~s}(p<$ $0.05)$, with Ti remaining the same $(0.60 \pm$ $0.05 s ; p>0.05)$.

In four cases, stimulation of the caudal ventrolateral PAG elicited a respiratory response characterized by irregular breathing interspersed by episodes of apnea and no vocalization (Fig. 8C). The apneas extended up to $5 \mathrm{~s}$. The diaphragm EMG differed from burst to burst during the effect period but did not exhibit any postinspiratory activity. There was a small increase in respiratory frequency from $40 \pm 2$ to $48 \pm 2$ breaths $/ \min (p<$ $0.05)$. This respiratory response was accompanied by a decrease in blood pressure [from $105 \pm 5$ to $85 \pm 6 \mathrm{mmHg}(n=4 ; p<0.05)$ ] and heart rate [from $199 \pm 5$ to $160 \pm 5$ beats $/ \min (p<0.05)]$.

\section{Discussion}

The present investigation in the cat provides the first demonstration that different regions of the PAG have different effects on breathing. Our data demonstrate that the PAG is able to convert eupneic breathing into a breathing pattern that fits the particular behavior necessary for survival in specific circumstances. Three other studies in the cat (Zhang et al., 1994; Nonaka et al., 1999; Nakazawa et al., 2000) examined the role of the PAG in vocalization or fictive vocalization but not respiration. Moreover, none of these studies explores stereotaxically the influence of different areas of the PAG on respiratory function. Subramanian et al. (2007, 2008) studied the PAG-induced changes to caudal medullary respiration-related neuronal activity in the rat, and Huang et al. (2000) also in the rat investigated the role of the PAG on cardiorespiratory control, and subsequently Hayward et al. $(2003,2004)$ and Zhang et al. $(2005,2007)$ examined the PAG- induced change to respiratory frequency. However, all these studies in the rat focused on the dorsal PAG and reported only excitatory effects. In the present study in the cat, we show that not only excitatory but also inhibitory effects can be evoked from the PAG. Another major problem is that the rat studies used anesthetized preparations. Anesthesia is a major problem in studying respiration, because it suppresses the respiratory responses that can be evoked by stimulation in various brainstem areas (Batsel, 1965; McDougall et al., 2008; Peters et al., 2008). It means that chemical activation in anesthetized animals never provides conclusive results. Because our data have been obtained in decerebrate, unanesthetized cats, they closely resemble the effects that will be observed after PAG activation in unanesthetized animals or humans, albeit that the influence from higher brain levels on the brainstem is missing.

\section{Midbrain-brainstem respiratory pathways}

The PAG has no direct connections with any motoneuronal cell group in brainstem and spinal cord. To achieve effects on motor 


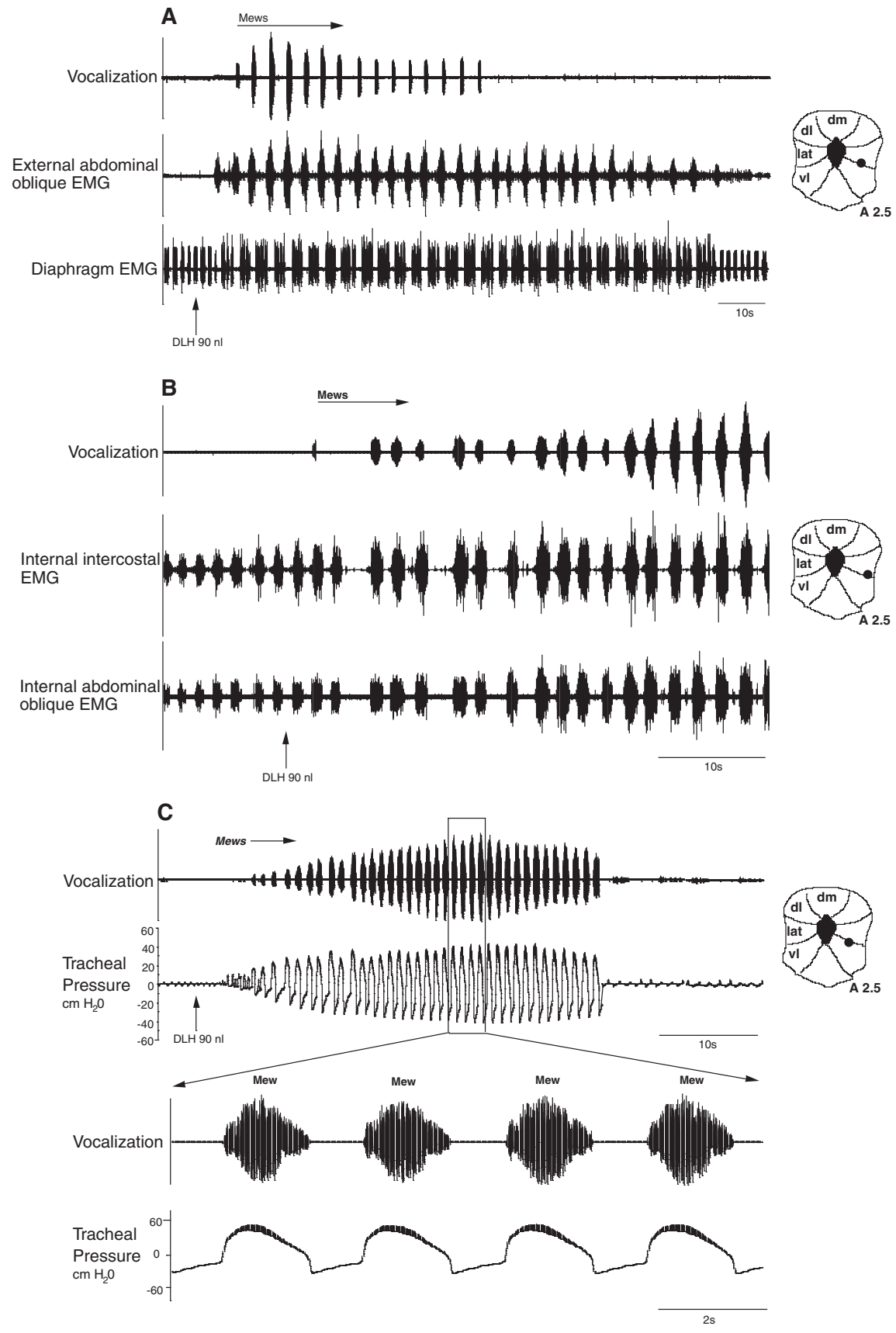

Figure 6. Recruitment of external abdominal oblique muscles $(\boldsymbol{A})$, internal intercostal and internal oblique muscles $(\boldsymbol{B})$, and increase in the tracheal pressure $(\boldsymbol{C})$ during lateral PAG induced vocalization.
Kuypers, 1982), but neurons in this region also excite other bulbospinal and propriobulbar inspiratory cells (Ezure et al., 1989). The nucleus of the solitary tract in the cat contains inspiratory neurons (von Baumgarten and Kanzow, 1958; Berger, 1977) that drive the phrenic (Lipski et al., 1983) and external intercostal motoneurons through direct connections (Holstege and Kuypers, 1982; Duffin and Lipski, 1987). Cells in the rostral part of the nucleus retroambiguus play a role in inspiration and several other motor output systems by way of their projections to the nucleus ambiguus (Holstege, 1989), the phrenic nucleus, and the external intercostal motoneurons (Holstege and Kuypers, 1982; Miller et al., 1989). Neurons in the caudal NRA, however, play a role in expiration and many other motor functions via their projections to abdominal, internal intercostal, pelvic floor, and several other motoneuronal cell groups (Holstege, 1991b). In short, the PAG uses the respiration-related cell groups to integrate respiration in the context of organizing specific survival behavior. In the rat, stimulation in the dorsal PAG has been shown to result in phasic excitation of lateral parabrachial inspiration-related neurons (Hayward et al., 2004) and in both phasic and tonic activation of inspiration- and expirationrelated neurons in the ventrolateral medulla (Subramanian et al., 2008) and nucleus tractus solitarius (Subramanian et al., 2007). The involvement of $\beta$-adrenoceptors within the NTS mediating the PAG-induced respiratory and cardiovascular effect has also been previously reported in the rat (Huang et al., 2000; Subramanian et al., 2007). Obviously, the basic behavioral repertoire in the PAG is further evolved in cat than in rat; however, in the cat, there are no electrophysiological data presently available on the PAG effects on the brainstem respiration-related nuclei. output, it uses premotor interneurons involved in coordination of motor output. Also for producing changes in breathing, the PAG uses respiration-related premotor interneurons in the brainstem. In the cat, it projects to the parabrachial and Kolliker-Fuse nuclei (Holstege, 1991a), the retrofacial nucleus (Kobayashi et al., 1994; Sakamoto et al., 1996), the solitary nucleus (NTS) (Bandler and Tork, 1987), and the nucleus retroambiguus (NRA) (Holstege, 1989). The pontine respiratory groups maintain direct projections to the phrenic nucleus (Holstege and Kuypers, 1982) and have been proposed to play an important role in the modulation of respiratory reflexes, such as phase-switching (Alheid et al., 2004). The retrofacial region in the rostral medulla contains inspiratory neurons that project directly to the phrenic motoneurons (Holstege and
Dorsomedial PAG stimulation produces dyspnea

The dorsomedial PAG is strongly implicated in the mediation of fear and anxiety and associated defensive responses (Bandler and Carrive, 1988; Bandler and Depaulis, 1991). The slow and deep breathing as we elicited in the dorsomedial PAG may fit such a fear reaction. The expiratory apneusis we also observed corresponds with Duggan and Morton (1983), who found that, in anesthetized cats, stimulation in the dorsal PAG increases expiratory $\mathrm{CO}_{2}$.

Dorsolateral PAG produces increased respiratory effort

Both defensive and aversive responses are elicited by stimulating the dorsolateral PAG. This includes threat and confrontational behaviors as well as flight response (Bandler and Depaulis, 1991). For such confrontational behaviors, active 
expiration and increased respiratory effort are required. A flight reaction requires an immediate increase of the respiratory frequency, effort, and oxygen sufficiency. The diaphragm amplitude increases twofold within two breaths after the onset of response. This sudden and large increase signifies an abrupt increase in respiratory effort required to escape or confront a dangerous situation. This sudden rise in diaphragm amplitude also produces an increase in the functional residual capacity necessary for higher oxygen level that is required for a flight or a fight. Thus, the conversion of passive breathing to active breathing we elicited in the dorsolateral PAG fits its role in appropriating defensive or aversive behavior.

\section{Lateral PAG induces \\ inspiratory apneusis}

Another important finding is the inspiratory apneusis induced by stimulation in the lateral PAG. According to von Euler (1983), inspiratory apneusis is also present after bilateral lesions in the parabrachial nuclei, which led to the concept that the parabrachial nuclei constitute the pneumotaxic center in the brainstem. The present results suggest that the lateral PAG has access to this pneumotaxic breathing circuitry, because stimulation in the medial part of the lateral PAG inhibits the inspiratory offswitch function, permitting inspiration to continue for longer periods of time. The lateral PAG may also play a role in the expansion of inspiratory time observed in cats during rapid eye movement sleep ( $\mathrm{Ni}$ et al., 1990; Orem and Anderson, 1996).

\section{Respiratory changes during vocal behavior}

Vocalization is an important tool in survival behavior. To produce vocalization, the animal needs sufficient air volume and air pressure (Davis et al., 1993) for which the PAG controls expiration as well as inspiration, probably via its projections to the NRA. This explains why stimulation in the lateral PAG resulted not only in a small decrease in Ti before a mew but also that during this Ti large amplitude spikes appeared in the diaphragm EMG. These spikes produce the increase of lung volume necessary for vocalization. Vocalization also requires expiratory facilitation. The present results show that the PAG induces an expiratory drive by recruiting the internal intercostal and internal and external abdominal oblique muscles before a mew. According to Shiba et al. (1997) in the cat, expiration-related neurons and other "silent" cells in the nucleus retroambiguus as well as neurons in the reticular formation medially adjoining the NRA are activated by the PAG and could play an important role in shaping the vocal expiratory out- flow. The large increases in the tracheal pressure (up to $40 \mathrm{~cm}$ $\mathrm{H}_{2} \mathrm{O}$ ) demonstrate that the PAG integrates the expiratory and laryngeal activity required for the generation of vocalization.

\section{Caudal ventrolateral PAG induces irregular breathing}

Stimulation in the caudal ventrolateral PAG produces freezing and immobility (Bandler and Carrive, 1988; Bandler and Depaulis, 1991). A strong freezing reaction is regarded as a salient index of fear or anxiety in humans (Gray and McNaughton, 1996). The respiratory effect after stimulation in the caudal ventrolateral PAG corresponds with freezing behavior. This was characterized by a momentary increase in respiratory frequency followed by respiratory depression and an increase in the diaphragmatic EMG signal inter- 

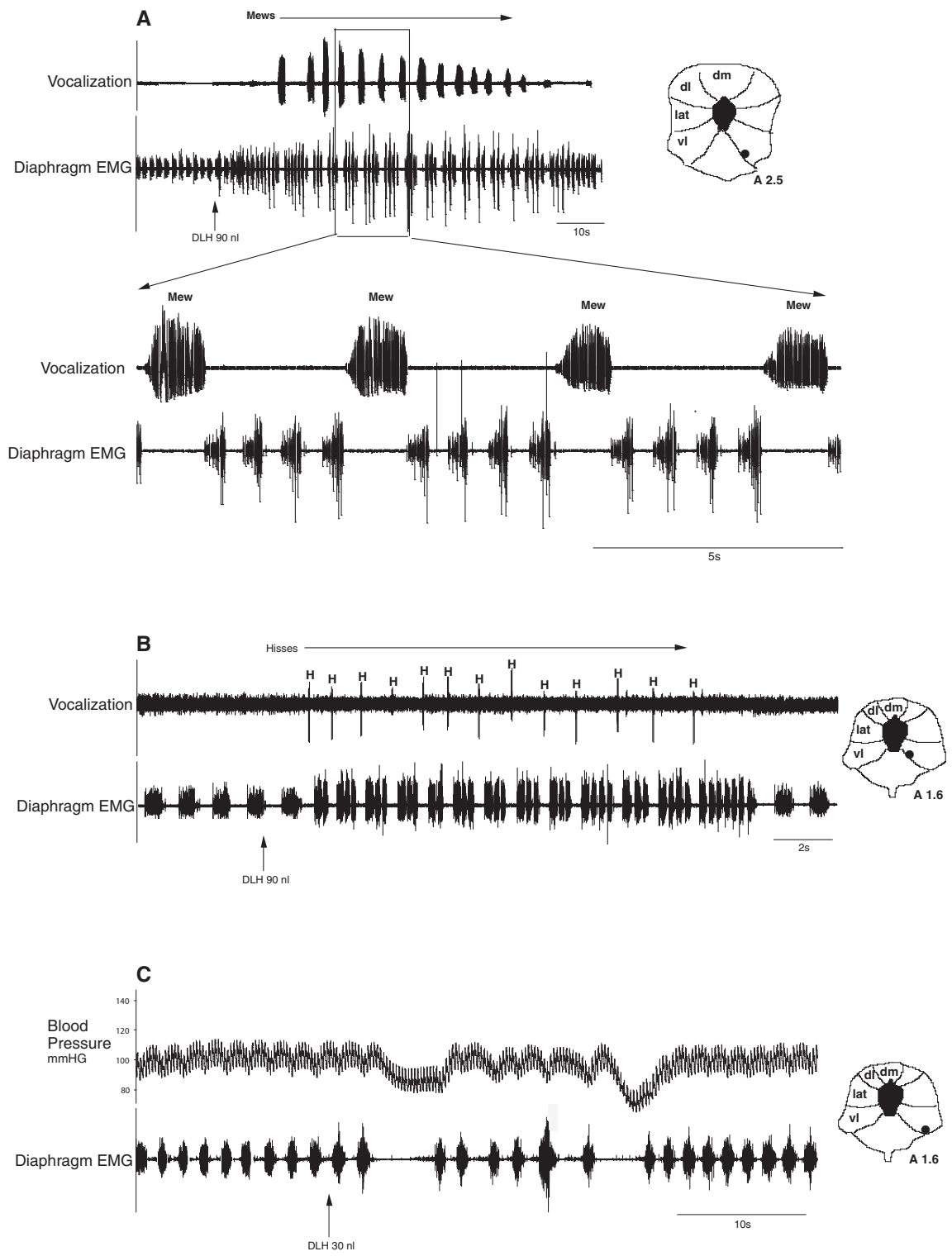

Figure 8. A, Multiple diaphragm breathing pattern characterized by several short inspirations before a mew elicited from the ventrolateral PAG. $\boldsymbol{B}$, Train of hisses evoked after DLH injection into the ventrolateral PAG (H, hiss). $\boldsymbol{C}$, Respiratory response evoked after DLH injection into the caudal ventrolateral PAG.

spersed with episodes of apnea. Hypotension was also seen during this stimulation. The poststimulus recovery of breathing, before the return to normalcy, was marked by an increase in the respiratory frequency, which signifies postdefense recuperative behavior.

\section{Dose-response}

Responses elicited in the PAG were dose dependant. A 6-15 nl DLH injection anywhere in the PAG did not produce any change in respiration. For a pronounced effect, a minimum of $30 \mathrm{nl}$ microinjections was required. In the dorsomedial and dorsolateral PAG, DLH injections $>30 \mathrm{nl}$ produced an additional increase or decrease in the respiratory frequency and associated cardiovascular effects. Injections $>60 \mathrm{nl}$ were not attempted in the dorsomedial PAG because of eventual prolongation of apnea beyond $10 \mathrm{~s}$, which might be detrimental to the health of the animal. Vocalization types as growling or howling were never elicited in our study. Perhaps the elimination of prefrontal and subcortical projections to the PAG in a decerebrate preparation plays a role.

\section{PAG controls breathing in the context of survival behavior}

Traditionally, the PAG has not been considered to play a part in the brainstem nuclei associated with respiration. However, PAG lesioning renders the animals mute and makes them incapable of fully exhibiting complex behavior such as anxiety or aggression (Adametz and O'Leary, 1959). The elimination of the PAG control of respiratory neuronal circuitry may contribute to the animal's inability to physically express emotions. Our results also support previous observations on the role of PAG in correlating respiratory and intralaryngeal activity not only in cats (Magoun et al., 1937; Bandler and Carrive, 1988; Davis et al., 1993; Zhang et al., 1994; Shiba et al., 1997) but also in monkey (Jürgens and Pratt, 1979; Larson, 1985; Larson and Kistler, 1986) and humans (Mead and Reid, 1988; Holstege and Ehling, 1994). Our results demonstrate that the PAG has a similar control over respiration as over micturition, mating behavior, cardiovascular systems, nociception, and other levelsetting systems (Fig. 9), all in the context of integrated survival behavior of the individual and of the species.

\section{References}

Adametz J, O’Leary JL (1959) Experimental mutism resulting from periaqueductal lesions in cats. Neurology 9:636-642.

Alheid GF, Milsom WK, McCrimmon DR (2004) Pontine influences on breathing: an overview. Resp Physiol Neurobiol 143:105-114.

Bandler R, Carrive P (1988) Integrated defense reaction elicited by excitatory amino acid microinjection in the midbrain periaqueductal grey region of the unrestrained cat. Brain Res 439:95-106.

Bandler R, Depaulis A (1991) Midbrain periaqueductalgray control of defensive behavior in the cat and the rat. In: The midbrain periaqueductal gray matter: functional anatomical and immunohistochemical organization (Depaulis A, Bandler R, eds), pp 175-198. New York: Plenum.

Bandler R, Tork I (1987) Midbrain periaqueductal grey region in the cat has afferent and efferent connections with solitary tract nuclei. Neurosci Lett 74:1-6.

Batsel HL (1965) Some functional properties of bulbar respiratory units. Exp Neurol 11:341-366.

Behbehani MM (1995) Functional characteristics of the midbrain periaqueductal gray. Prog Neurobiol 46:575-605.

Berger AJ (1977) Dorsal respiratory group neurons in the medulla oblongata of cat: spinal projections, responses to lung inflation and superior laryngeal nerve stimulation. Brain Res 135:231-254.

Berman AL (1968) The brainstem of the cat: a cytoarchitectonic atlas with stereotaxic coordinates. Madison, WI: University of Wisconsin.

Davis PJ, Zhang SP, Bandler R (1993) Pulmonary and upper airway influences on the motor pattern of vocalization evoked by excitation of midbrain periaqueductal gray of the cat. Brain Res 607:61-80.

Duffin J, Lipski J (1987) Monosynaptic excitation of thoracic motoneurons 


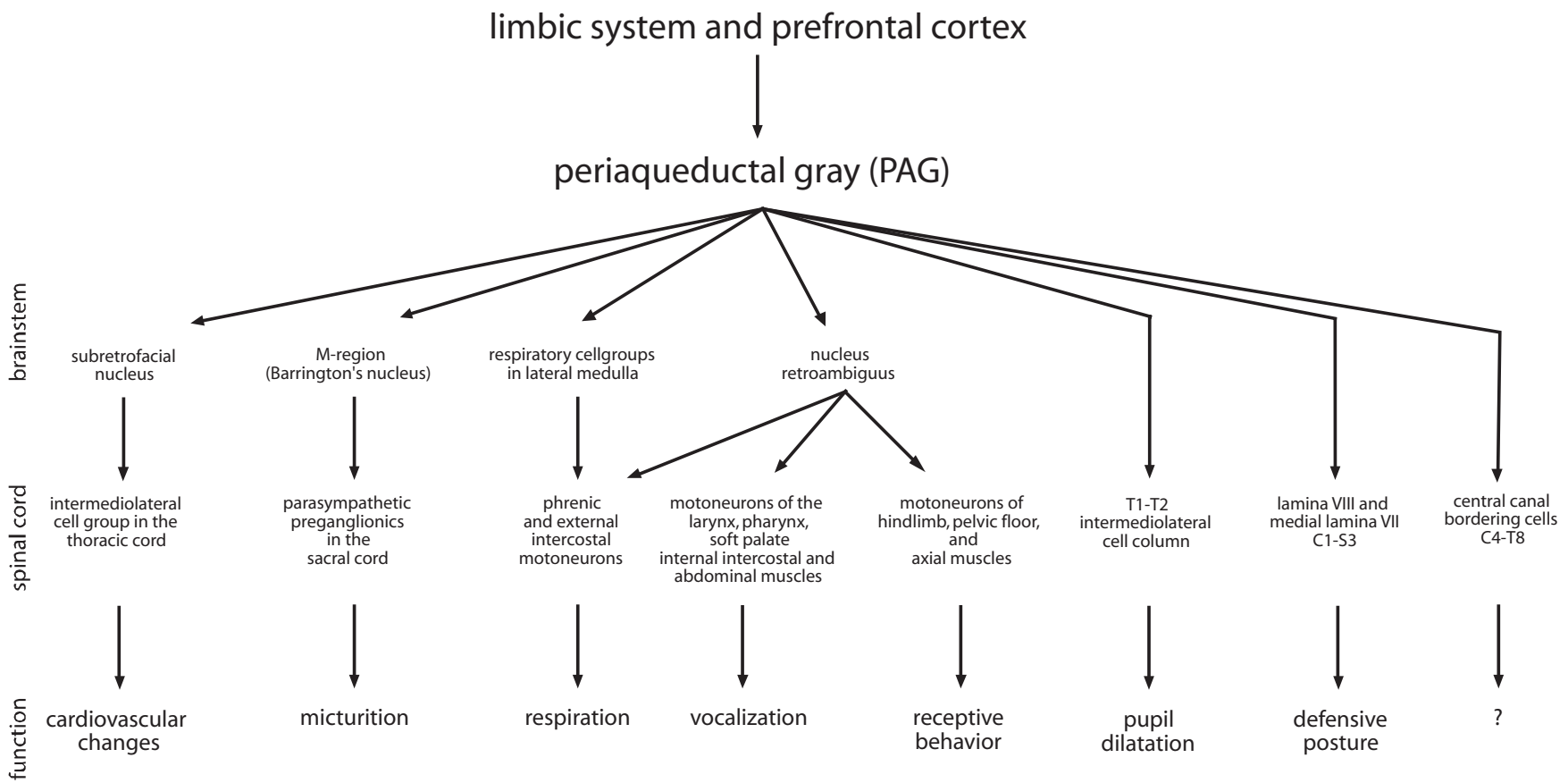

specific emotional behaviors

Figure 9. Diagram showing that respiration is one of several motor functions controlled by the periaqueductal gray. Together, they produce the behaviors necessary for basic survival of the individual and of the species.

by inspiratory neurones of the nucleus tractus solitarius in the cat. J Physiol 390:415-431.

Duggan AW, Morton CR (1983) Periaqueductal gray stimulation. An association between selective inhibition of dorsal horn neurones and changes in peripheral circulation. Pain 15:237-248.

Ezure K, Manabe M, Otake K (1989) Excitation and inhibition of medullary inspiratory neurons by two types of burst inspiratory neurons in the cat. Neurosci Lett 104:303-308.

Feldman JL (1986) Neurophysiology of breathing in mammals. In: Handbook of physiology. The nervous system. Intrinsic regulatory system in the brain, Vol 4, pp 463-524. Washington, DC: American Physiological Society.

Gray JA, McNaughton N (1996) The neuropsychology of anxiety: reprise. Nebr Symp Motiv 43:61-134.

Hayward LF, Swartz CL, Davenport PW (2003) Respiratory response to activation or disinhibition of the dorsal periaqueductal gray in rats. J Appl Physiol 94:913-922.

Hayward LF, Castellanos M, Davenport PW (2004) Parabrachial neurons mediate dorsal periaqueductal gray evoked respiratory responses in the rat. J Appl Physiol 96:1146-1154.

Holstege G (1989) Anatomical study of the final common pathway for vocalization in the cat. J Comp Neurol 284:242-252.

Holstege G (1991a) Descending pathways from the periaqueductal gray and adjacent areas. In: The midbrain periaqueductal gray matter: functional anatomical and immunohistochemical organization (Depaulis A, Bandler R, eds), pp 239-265. New York: Plenum.

Holstege G (1991b) Descending motor pathways and the spinal motor system. Limbic and non-limbic components. In: Progress in brain research, Vol 87 (Holstege G, ed), pp 307-421. Amsterdam: Elsevier.

Holstege G, Ehling T (1994) Two motor systems involved in the production of speech. In: Vocal fold physiology; controlling complexity and chaos (Davis PJ, Fletcher H, eds), pp 153-169. London: Singular.

Holstege G, Kuypers HG (1982) The anatomy of brainstem pathways to the spinal cord in cat. A labeled amino acid tracing study. Prog Brain Res $57: 145-175$

Huang ZG, Subramanian SH, Balnave RJ, Turman AB, Moi Chow C (2000) Roles of periaqueductal gray and nucleus tractus solitarius in cardiorespiratory function in the rat brainstem. Respir Physiol 120:185-195.
Jürgens U, Pratt R (1979) Role of periaqueductal gray in vocal expression of emotion. Brain Res 167:367-378.

Kobayashi Y, Katada A, Myoga H, Sakamoto T (1994) A PHA-L study on the descending pathway for vocalization from the periaqueductal gray to the lower brainstem in cats. Soc Neurosci Abstr 20:1407.

Larson CR (1985) The midbrain periaqueductal gray: a brainstem structure involved in vocalization. J Speech Hear Res 28:241-249.

Larson CR, Kistler MK (1986) The relationship of periaqueductal gray neurons to vocalization and laryngeal EMG in the behaving monkey. Exp Brain Res 63:596-606.

Lipski J, Kubin L, Jodkowski J (1983) Synaptic action of R $\beta$ neurons on phrenic motoneurons studied with spike-triggered averaging. Brain Res 288:105-118.

Long S, Duffin J (1986) Neuronal determinants of respiratory rhythm. Prog Neurobiol 27:101-182.

Magoun HW, Atlas D, Ingersoll EH, Ranson SW (1937) Associated facial, vocal and respiratory components of emotional expression: an experimental study. J Neurol Psychopath 17:241-255.

McDougall SJ, Bailey TW, Mendelowitz D, Andresen MC (2008) Propofol enhances both tonic and phasic inhibitory currents in second order neurons of solitary tract nucleus. Neuropharmacology 54:552-563.

Mead J, Reid MB (1988) Respiratory muscle activity during repeated airflow interruption. J Appl Physiol 64:2314-2317.

Miller AD, Tan LK, Lakos SF (1989) Brainstem projections to cats' upper lumbar spinal cord: implications for abdominal muscle control. Brain Res 493:348-356

Nakazawa K, Granata AR, Cohen MI (2000) Synchronized fast rhythms in inspiratory and expiratory nerve discharges during fictive vocalization. J Neurophysiol 83:1415-1425.

Ni HF, Zhang JX, Harper RM (1990) Respiratory-related discharge of periaqueductal gray neurons during sleep-awake states. Brain Res 511:319-325.

Nonaka S, Takahashi R, Enomoto K, Katada A, Unno T (1997) Lombard reflex during PAG-induced vocalization in decerebrate cats. Neurosci Res 29:283-289.

Orem J, Anderson CA (1996) Diaphragmatic activity during REM sleep in the adult cat. J Appl Physiol 81:751-760.

Peters JH, McDougall SJ, Mendelowitz D, Koop DR, Andresen MC (2008) 
Isofluorane differentially modulates inhibitory and excitatory synaptic transmission to the solitary nucleus. Anesthesiology 108:675-683.

Sakamoto T, Nonaka S, Katada T (1996) Control of respiratory muscles during speech and vocalization. In: Neural control of respiratory muscles (Miller AD, Bianchi AL, Bishop BP, eds), pp 249-258. Boca Raton, FL: CRC.

Shiba K, Umezaki T, Zheng Y, Miller AD (1997) The nucleus retroambigualis controls laryngeal muscle activity during vocalization in the cat. Exp Brain Res 115:513-519.

Subramanian HH, Chow CM, Balnave RJ (2007) Identification of different types of respiratory neurones in the dorsal brainstem nucleus tractus solitarius of the rat. Brain Res 1141:119-132.

Subramanian H, Huang ZG, Balnave R (2008) Responses of brainstem respiratory neurons to activation of midbrain periaqueductal gray in the rat. Adv Exp Med Biol 605:377-381. von Baumgarten R, Kanzow E (1958) The interaction of two types of inspiratory neurons in the region of the tractus solitarius of the cat. Arch Ital Biol 96:361-373.

von Euler C (1983) On the central pattern generator for the basic breathing rhythmicity. J Appl Physiol 55:1647-1659.

Zhang SP, Davis PJ, Bandler R, Carrive P (1994) Brain stem integration of vocalization: role of midbrain periaqueductal gray. J Neurophysiol 72:1337-1356.

Zhang W, Hayward LF, Davenport PW (2005) Respiratory muscle responses elicited by dorsal periaqueductal gray stimulation in rats. Am J Physiol Regul Integr Comp Physiol 289:R1338-R1347.

Zhang W, Hayward LF, Davenport PW (2007) Respiratory responses elicited by rostral versus caudal dorsal periaqueductal gray stimulation in rats. Auton Neurosci 134:45-54. 